\title{
Kinematic Analysis of Five Different Anterior Cruciate Ligament Reconstruction Techniques
}

\author{
Hemanth R Gadikota, PhD, Ali Hosseini, PhD, Peter Asnis, MD, and Guoan Li, PhD \\ Bioengineering Laboratory, Department of Orthopaedic Surgery, Massachusetts General Hospital and Harvard Medical School, Boston, MA, USA
}

\begin{abstract}
Several anatomical anterior cruciate ligament (ACL) reconstruction techniques have been proposed to restore normal joint kinematics. However, the relative superiorities of these techniques with one another and traditional single-bundle reconstructions are unclear. Kinematic responses of five previously reported reconstruction techniques (single-bundle reconstruction using a bone-patellar tendon-bone graft [SBR-BPTB], single-bundle reconstruction using a hamstring tendon graft [SBR-HST], single-tunnel double-bundle reconstruction using a hamstring tendon graft [STDBRHST], anatomical single-tunnel reconstruction using a hamstring tendon graft [ASTR-HST], and a double-tunnel double-bundle reconstruction using a hamstring tendon graft [DBR-HST]) were systematically analyzed. The knee kinematics were determined under anterior tibial load (134 N) and simulated quadriceps load $(400 \mathrm{~N})$ at $0^{\circ}, 15^{\circ}, 30^{\circ}, 60^{\circ}$, and $90^{\circ}$ of flexion using a robotic testing system. Anterior joint stability under anterior tibial load was qualified as normal for ASTR-HST and DBR-HST and nearly normal for SBR-BPTB, SBR-HST, and STDBR-HST as per the International Knee Documentation Committee knee examination form categorization. The analysis of this study also demonstrated that SBR-BPTB, STDBRHST, ASTR-HST, and DBR-HST restored the anterior joint stability to normal condition while the SBR-HST resulted in a nearly normal anterior joint stability under the action of simulated quadriceps load. The medial-lateral translations were restored to normal level by all the reconstructions. The internal tibial rotations under the simulated muscle load were over-constrained by all the reconstruction techniques, and more so by the DBRHST. All five ACL reconstruction techniques could provide either normal or nearly normal anterior joint stability; however, the techniques overconstrained internal tibial rotation under the simulated quadriceps load.
\end{abstract}

Keywords: Anterior cruciate ligament, Anatomical reconstruction, Single-bundle, Knee kinematics, Robotic testing system

\section{Introduction}

Anterior cruciate ligament (ACL) reconstruction has been widely accepted to be the standard of care for patients who sustain an ACL rupture to minimize the risk of further meniscal and chondral injuries, facilitate pre-injury level of activity, and to prevent posttraumatic osteoarthritis ${ }^{1-3)}$. Although ACL recon-

Received February 4, 2015; Revised March 5, 2015;

Accepted April 16, 2015

Correspondence to: Guoan $\mathrm{Li}, \mathrm{PhD}$

Bioengineering Laboratory, Department of Orthopaedic Surgery, Massachusetts General Hospital/Harvard Medical School, 55 Fruit Street - GRJ 1215, Boston, MA 02114, USA

Tel: +1-617-726-6472, Fax: +1-617-724-4392

E-mail: gli1@mgh.harvard.edu

This is an Open Access article distributed under the terms of the Creative Commons Attribution Non-Commercial License (http://creativecommons.org/licenses/by-nc/4.0/) which permits unrestricted non-commercial use, distribution, and reproduction in any medium, provided the original work is properly cited. struction reduces the risk of secondary meniscal tears, a large percentage of ACL reconstructed patients have been reported to have radiographic evidence of osteoarthritis after surgery ${ }^{4-8)}$ and that only 66 to $76 \%$ of the patients return to their pre-injury level of activities ${ }^{9,10)}$. In addition, postoperative rotational instability, such as repeated episodes of giving-way in high-demand as well as daily living activities, has often been cited as a concern to ACL reconstructed patients ${ }^{3,11-13)}$. Widely practiced surgical techniques have yet to prove their efficacy in restoring normal knee joint function and preventing long term joint degeneration.

Sub-optimal performance of single-bundle ACL reconstruction has sparked a renewed interest in anatomical reconstruction techniques and alterations to the conventional techniques, such as creating a more horizontal femoral tunnel ${ }^{14-17)}$. In an attempt to reproduce the native anatomical two-bundle structure of the ACL, double-bundle ACL reconstruction has been advocated by some investigators. Among the biomechanical studies, significant improvements in joint stability have been reported following 
double-bundle ACL reconstruction compared to single-bundle reconstruction ${ }^{18-20)}$. However, such improvements in patients' outcomes are yet to be established and hence many surgeons remain skeptical on practicing these technically challenging procedures $^{21)}$. In an effort to minimize procedural complications while providing uncompromised joint stability, several authors have proposed innovative techniques to reproduce the two bundles of the ACL using the conventional single tibial and femoral tunnels familiar to all practicing sports medicine surgeons ${ }^{14,22-26}$. While these various ACL reconstruction techniques have been shown to have different advantages in restoration of knee biomechanics, the relative superiorities of these techniques with one another is unclear.

As the ACL reconstruction techniques continue to evolve, our laboratory had the opportunity to conduct a series of in-vitro ro- botic experiments to evaluate the efficacies of five different reconstructive techniques in restoring normal six-degrees-of-freedom (6DOF) kinematics of the knee. Among the five reconstructions evaluated, two were traditional single-tunnel single-bundle techniques using either a bone-patellar tendon-bone ${ }^{27)}$ or a quadruple hamstring tendon ${ }^{18)}$ autografts, and the three relatively new anatomical techniques that used quadruple hamstrang tendon autografts were a single-tunnel double-bundle technique ${ }^{14)}$, doubletunnel double-bundle technique ${ }^{18)}$, and an anatomical singletunnel technique ${ }^{24)}$. The data from these studies indicated that each ACL reconstruction may have a unique advantage in restoration of normal knee biomechanics. Therefore, the objective of this study was to systematically compare the 6DOF knee joint kinematics of these five ACL reconstruction techniques. The hypothesis of this study was that anatomical ACL reconstructions

Table 1. A Summary of Four Anterior Cruciate Ligament (ACL) Reconstruction Techniques

\begin{tabular}{|c|c|c|c|c|c|}
\hline $\begin{array}{l}\text { Reconstruction } \\
\text { technique }\end{array}$ & Graft source & Tunnel position & Implant & $\begin{array}{c}\text { Graft fixation } \\
\text { protocol }\end{array}$ & $\begin{array}{l}\text { Age of knee } \\
\text { specimens } \\
\text { (yr, range) }\end{array}$ \\
\hline \multirow[t]{2}{*}{ SBR } & $\begin{array}{l}\text { Bone-patellar } \\
\text { tendon-bone } \\
\text { autograft }\end{array}$ & $\begin{array}{l}\text { Two-incision technique was used } \\
\text { Femur: outside-in tunnel at } 11 / 1 \\
\text { oclock position } \\
\text { Tibia: } 7 \text { mm anterior to the PCL and } \\
7 \text { mm lateral to the medial femoral } \\
\text { condyle }\end{array}$ & $\begin{array}{l}\text { Femur: interference screw } \\
\text { (Depuy Mitek) } \\
\text { Tibia: interference screw } \\
\text { (Depuy Mitek) }\end{array}$ & $\begin{array}{l}\text { Initial graft tension: } \\
40 \mathrm{~N} \\
\text { Knee flexion angle: } \\
\text { full extension }\end{array}$ & $52-78$ \\
\hline & $\begin{array}{l}\text { Quadruple } \\
\text { hamstring } \\
\text { tendon autograft }\end{array}$ & $\begin{array}{l}\text { Femur: through anteromedial portal } \\
\text { at 10:30/1:30 oclock position } \\
\text { Tibia: center of ACL footprint at an } \\
\text { angle of } 55^{\circ}\end{array}$ & $\begin{array}{l}\text { Femur: EndoButton } \\
\text { CL (Smith \& Nephew } \\
\text { Endoscopy) } \\
\text { Tibia: Tibial INTRAFIX } \\
\text { system (Depuy Mitek) }\end{array}$ & $\begin{array}{l}\text { Initial graft tension: } \\
40 \mathrm{~N} \\
\text { Knee flexion angle: } \\
\text { full extension }\end{array}$ & $47-60$ \\
\hline STDBR & $\begin{array}{l}\text { Quadruple } \\
\text { hamstring } \\
\text { tendon autograft }\end{array}$ & $\begin{array}{l}\text { Femur: created transtibially at } 10 / 2 \\
\text { oclock position } \\
\text { Tibia: center of ACL remnant }\end{array}$ & $\begin{array}{l}\text { Femur: AperFix Femoral } \\
\text { Implant (Cayenne Medical) } \\
\text { Tibia: AperFix Tibial Implant } \\
\text { (Cayenne Medical) }\end{array}$ & $\begin{array}{l}\text { Initial graft tension: } \\
40 \mathrm{~N} \\
\text { Knee flexion angle: } \\
\text { full extension }\end{array}$ & $47-60$ \\
\hline ASTR & $\begin{array}{l}\text { Quadruple } \\
\text { hamstring } \\
\text { tendon autograft }\end{array}$ & $\begin{array}{l}\text { Femur: through anteromedial portal } \\
\text { at 10:30/1:30 oclock position } \\
\text { Tibia: center of ACL footprint at an } \\
\text { angle of } 55^{\circ}\end{array}$ & $\begin{array}{l}\text { Femur: Femoral INTRAFIX } \\
\text { system (Depuy Mitek) } \\
\text { Tibia: Tibial INTRAFIX } \\
\text { system (Depuy Mitek) }\end{array}$ & $\begin{array}{l}\text { Initial graft tension: } \\
40 \mathrm{~N} \\
\text { Knee flexion angle: } \\
\text { full extension }\end{array}$ & $47-60$ \\
\hline DBR & $\begin{array}{l}\text { AM bundle: } \\
\text { semitendinosus } \\
\text { autograft } \\
\text { PL bundle: gracilis } \\
\text { autograft }\end{array}$ & $\begin{array}{l}\text { Femur: through anteromedial portal } \\
\text { at the center of AM and PL bundle } \\
\text { footprints } \\
\text { Tibia: } \\
\text { AM tunnel, at the center of AM } \\
\text { bundle footprint at an angle of } 45^{\circ} \\
\text { PL tunnel, at the center of PL bundle } \\
\text { footprint at an angle of } 55^{\circ}\end{array}$ & $\begin{array}{l}\text { Femur: EndoButton } \\
\text { CL (Smith \& Nephew } \\
\text { Endoscopy) for both AM } \\
\text { and PL bundles } \\
\text { Tibia: Interference screw } \\
\text { (Depuy Mitek) for both AM } \\
\text { and PL bundles }\end{array}$ & $\begin{array}{l}\text { Initial graft tension: } \\
20 \mathrm{~N} \text { for } \mathrm{AM} \\
\text { and } 20 \mathrm{~N} \text { for PL } \\
\text { bundles } \\
\text { Knee flexion angle: } \\
\mathrm{AM} \text { bundle was } \\
\text { fixed at } 60^{\circ} \text { and PL } \\
\text { was fixed at full } \\
\text { extension }\end{array}$ & $59-64$ \\
\hline
\end{tabular}

SBR: single-bundle reconstruction, PCL: posterior cruciate ligament, STDBR: single-tunnel double-bundle reconstruction, ASTR: anatomical single-tunnel reconstruction, DBR: double-bundle reconstruction, AM: anteromedial, PL: posterolateral. 
can more closely restore the intact knee kinematics than the traditionally practiced single-bundle ACL reconstructions.

\section{Materials and Methods}

Kinematic responses of five reconstruction techniques (singlebundle reconstruction using a bone-patellar tendon-bone graft [SBR-BPTB], single-bundle reconstruction using a hamstring tendon graft [SBR-HST], single-tunnel double-bundle reconstruction using a hamstring tendon graft [STDBR-HST], anatomical single-tunnel reconstruction using a hamstring tendon graft [ASTR-HST], and double-tunnel double-bundle reconstruction using a hamstring tendon graft [DBR-HST]) were evaluated in eight human cadaveric knee specimens for each of these reconstructions ${ }^{14,18,24,27)}$. The kinematic responses of these specimens following all of the reconstructions have been previously reported in the literature ${ }^{14,18,24,27)}$. All of the specimens were stored at $-20^{\circ} \mathrm{C}$ before they were thawed for 24 hours prior to the testing. Each specimen was prepared in a similar fashion as previously described in our studies to be tested using the robotic testing system. The operation of the robotic testing system to investigate the biomechanics of the knee joint has been detailed in the literature ${ }^{14,18,24,27)}$.

After installation of the specimen on the robotic testing system, the passive flexion path of each specimen was determined from $0^{\circ}$ to $90^{\circ}$ of flexion for the specimens that underwent SBRBPTB and STDBR-HST reconstruction procedures and from $0^{\circ}$ to $120^{\circ}$ of flexion for the specimens in which SBR-HST, ASTRHST and DBR-HST reconstruction was performed. The passive flexion path is the combination of passive positions of the knee at $1^{\circ}$ intervals from $0^{\circ}$ to $90^{\circ}$ or $120^{\circ}$ of flexion. The passive position was recorded as the position of the tibia with respect to femur at which the forces and moments at the knee joint center were $<5 \mathrm{~N}$ and $<0.5 \mathrm{~N} \cdot \mathrm{m}$ respectively. Following determination of the passive path, each specimen with an intact ACL was subjected to two external loading conditions (anterior tibia load of $134 \mathrm{~N}$ and simulated quadriceps load of $400 \mathrm{~N}$ ) at $0^{\circ}, 15^{\circ}, 30^{\circ}, 60^{\circ}$ and $90^{\circ}$ of flexion, and the resulting tibiofemoral kinematics were recorded. Thereafter, the ACL was transected at the mid-substance to simulate an ACL deficient condition. Responses of the ACL deficient knee were then evaluated under the same protocol that was used to test the intact knee. The ACL of each specimen was then reconstructed by one of the five reconstruction techniques and the kinematics was determined under the two external loading conditions and at the five selected flexion angles. A summary of the surgical techniques used are presented in Table 1.

\section{Data Analysis}

In this study, the kinematic responses of the cadaveric knee specimens before and after a certain reconstruction were evaluated in the same specimen, i.e., each reconstructed specimen had its own control group which is the intact ACL condition of the specimen. Since the kinematics of the ACL intact and reconstructed knee were obtained from the same specimen, paired student's t-tests were used to determine if there were statistically significant differences between the two conditions at all flexion angles. The differences in the kinematics were considered statistically significant when $\mathrm{p}<0.05$.

\section{Results}

\section{Kinematic Responses to $134 \mathrm{~N}$ of Anterior Tibial Load}

Single-bundle ACL reconstruction using BPTB graft could not restore the normal anterior joint laxity at low flexion angles $\left(\leq 30^{\circ}\right)(\mathrm{p}<0.05)$. The residual laxity following SBR-BPTB ranged from $1.7 \pm 1.2 \mathrm{~mm}$ at full extension to $2.4 \pm 1.3 \mathrm{~mm}$ at $15^{\circ}$ of flexion (Fig. 1). Further, SBR-BPTB over-constrained the anteroposterior laxity beyond $60^{\circ}$ of flexion with a maximum over-constraint of $-2.1 \pm 2.6 \mathrm{~mm}$ at $90^{\circ}$ of flexion ( $\left.\mathrm{p}>0.05\right)$. Significant residual ante-

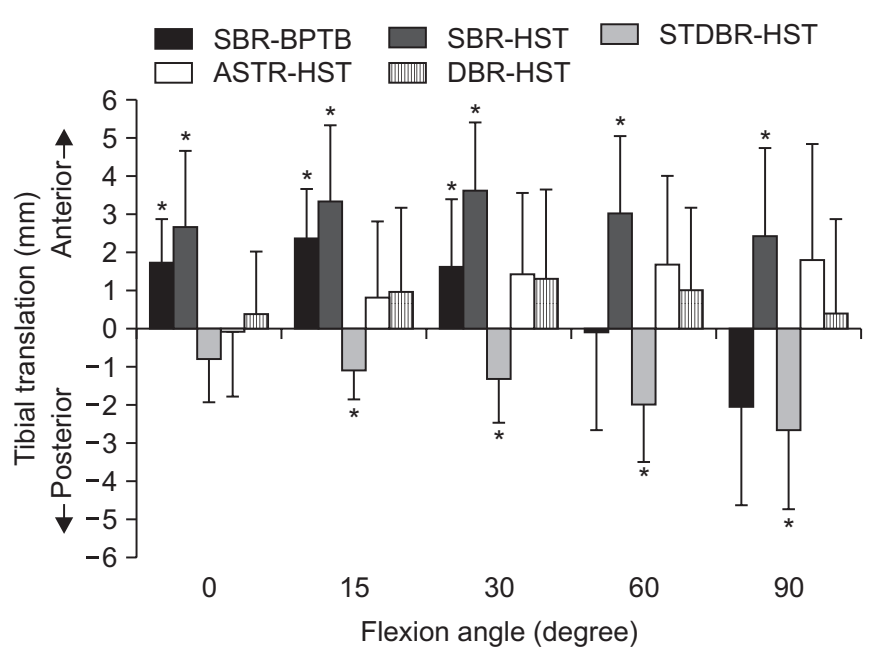

Fig. 1. The difference in anterior-posterior tibial translation between the intact knee and five anterior cruciate ligament (ACL) reconstructions under an anterior tibial load (134 N). Error bars represent standard deviations. SBR-BPTB: single-bundle reconstruction using a bone-patellar tendon-bone graft, SBR-HST: single-bundle reconstruction using a hamstring tendon graft, STDBR-HST: single-tunnel double-bundle reconstruction using a hamstring tendon graft, ASTR-HST: anatomical single-tunnel reconstruction using a hamstring tendon graft, DBR-HST: double-tunnel double-bundle reconstruction using a hamstring tendon graft.

${ }^{*} \mathrm{p}<0.05$; significantly different compared to ACL intact knee. 
rior laxities were observed at all selected flexion angles following SBR-HST $(\mathrm{p}<0.05)$. The maximum residual laxity of $3.6 \pm 1.8 \mathrm{~mm}$ occurred at $30^{\circ}$ flexion and the least residual laxity of $2.4 \pm 2.4 \mathrm{~mm}$ was observed at $90^{\circ}$ of flexion after SBR-HST. Anteroposterior joint laxity was significantly over-constrained by STDBR-HST between $15^{\circ}$ and $90^{\circ}$ of flexion $(\mathrm{p}<0.05)$. The amount of overconstraint observed due to STDBR-HST increased with knee flexion ranging from $-0.8 \pm 1.1 \mathrm{~mm}$ at full extension to $-2.7 \pm 2.0$ $\mathrm{mm}$ at $90^{\circ}$ of flexion. No significant differences were observed between the anterior laxity of intact knee and ASTR-HST conditions at all selected flexion angles $(\mathrm{p}<0.05)$. Maximum residual anterior laxity of $1.8 \pm 3.1 \mathrm{~mm}$ in knee specimens reconstructed by the anatomical single-tunnel technique was observed at $90^{\circ}$ of flexion. DBR-HST closely restored the normal anterior joint laxity at all selected flexion angles $(\mathrm{p}<0.05)$. The maximum anterior residual laxity after DBR-HST was $1.3 \pm 2.3 \mathrm{~mm}$, which occurred at $30^{\circ}$ of flexion.

\section{Kinematic Responses to $400 \mathrm{~N}$ of Simulated Quadriceps Load}

No significant differences were observed between the anterior laxities of intact knee and SBR-BPTB conditions at all selected flexion angles ( $\mathrm{p}<0.05)$ (Fig. 2). However, SBR-BPTB over-constrained the joint beyond $30^{\circ}$ of flexion with a maximum over- constraint of $-1.6 \pm 2.5 \mathrm{~mm}$ at $90^{\circ}$ of flexion $(\mathrm{p}<0.05)$. Significant residual laxities were observed following SBR-HST at $0^{\circ}, 15^{\circ}$, and $30^{\circ}$ of flexion $(\mathrm{p}<0.05)$. Maximum anterior laxity of $2.5 \pm 2.0 \mathrm{~mm}$ was observed at $15^{\circ}$ of flexion after SBR-HST. Single-tunnel double-bundle reconstruction closely restored the normal anteroposterior joint laxity at low flexion angles $\left(\leq 30^{\circ}\right)(\mathrm{p}<0.05)$. However, it significantly over-constrained the anteroposterior joint laxity at $60^{\circ}$ and $90^{\circ}$ of flexion $(\mathrm{p}<0.05)$. Both ASTR-HST and DBR-HST closely restored the normal anterior joint laxity at all selected flexion angles $(p<0.05)$. The residual anteroposterior joint laxities following either ASTR-HST or DBR-HST were below $1 \mathrm{~mm}$ at all selected flexion angles.

The medial-lateral positions of the tibia with respect to the femur of all the five reconstruction techniques were not significantly different compared to their respective intact knee conditions at all selected flexion angles $(\mathrm{p}<0.05)$ (Fig. 3). However, the tibiae of the SBR-BPTB and SBR-HST conditions were more medially located while the tibiae of STDBR-HST, ASTR-HST, and DBR-HST were more laterally located compared to their respective intact knee tibiae. A maximum medial tibial shift of $0.8 \pm 1.1 \mathrm{~mm}$ was observed at $30^{\circ}$ of flexion after SBR-HST and a maximum lateral tibial shift of $-0.7 \pm 1.1 \mathrm{~mm}$ occurred at $60^{\circ}$ of flexion following STDBR-HST.

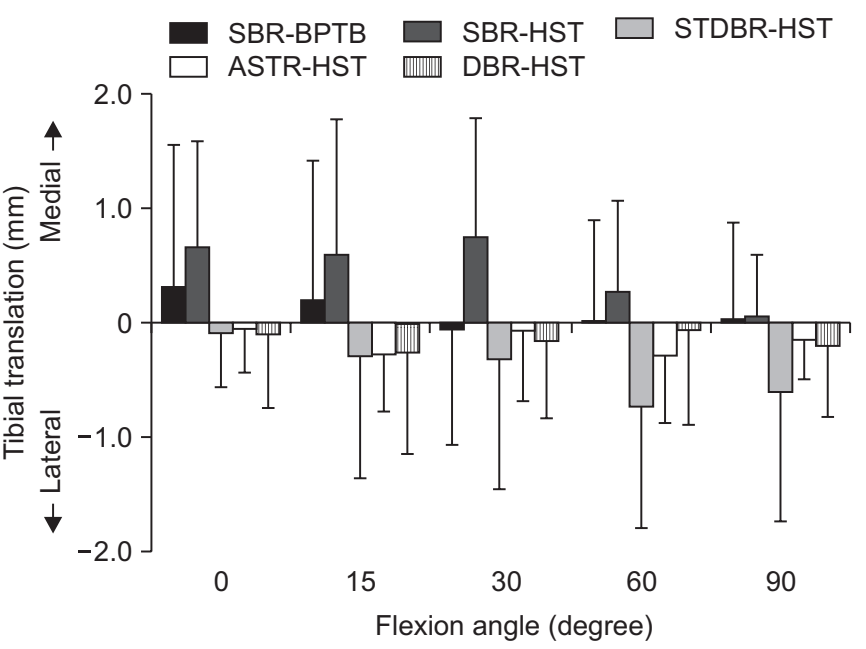

Fig. 3. The difference in medial-lateral tibial translation between the intact knee and five anterior cruciate ligament (ACL) reconstructions under simulated quadriceps load $(400 \mathrm{~N})$. Error bars represent standard deviations. SBR-BPTB: single-bundle reconstruction using a bonepatellar tendon-bone graft, SBR-HST: single-bundle reconstruction using a hamstring tendon graft, STDBR-HST: single-tunnel double-bundle reconstruction using a hamstring tendon graft, ASTR-HST: anatomical single-tunnel reconstruction using a hamstring tendon graft, DBR-HST: double-tunnel double-bundle reconstruction using a hamstring tendon graft.

${ }^{*} \mathrm{p}<0.05$; significantly different compared to ACL intact knee. 


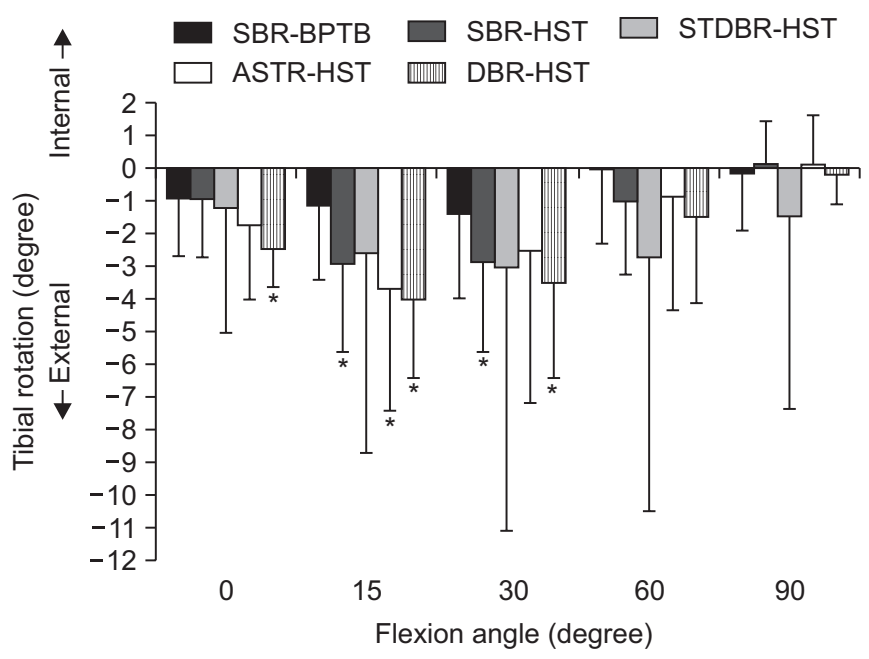

Fig. 4. The difference in internal-external tibial rotations between the intact knee and five anterior cruciate ligament (ACL) reconstructions under simulated quadriceps load (400 N). Error bars represent standard deviations. SBR-BPTB: single-bundle reconstruction using a bonepatellar tendon-bone graft, SBR-HST: single-bundle reconstruction using a hamstring tendon graft, STDBR-HST: single-tunnel double-bundle reconstruction using a hamstring tendon graft, ASTR-HST: anatomical single-tunnel reconstruction using a hamstring tendon graft, DBR-HST: double-tunnel double-bundle reconstruction using a hamstring tendon graft.

${ }^{\star} \mathrm{p}<0.05$; significantly different compared to ACL intact knee.

All the five reconstruction techniques induced an increase in external tibial rotation compared to the intact knee condition (Fig. 4). The tibial internal-external rotations were best restored to the normal condition by SBR-BPTB at all selected flexion angles compared to the other four reconstructions. Among the five reconstruction techniques, DBR-HST induced the largest external tibial rotations compared to the intact knee at low flexion angles $\left(\leq 30^{\circ}\right)(\mathrm{p}<0.05)$. The maximum external tibial rotation $\left(-4.0^{\circ} \pm 2.4^{\circ}\right)$ compared to the intact knee condition was observed at $15^{\circ}$ of flexion following DBR-HST.

\section{Discussion}

As the efforts to further optimize the surgical techniques for a ruptured ACL continue in sports medicine, recent literature suggests an inclination of these efforts towards more anatomical approaches. The purpose of this study was to systematically compare the two widely adopted traditional single-bundle reconstruction techniques to three relatively new anatomical approaches in restoring normal knee biomechanics. Our hypothesis that anatomical ACL reconstructions can more closely restore the normal knee kinematics than traditional SB ACL reconstructions was partially supported by the findings of this analysis. More specifically, the reconstructed knees were qualified as normal following ASTR-HST and DBR-HST and nearly normal following SBRBPTB, SBR-HST and STDBR-HST as per the International Knee Documentation Committee knee examination form categorization based on the anterior stability under anterior tibial load. The internal tibial rotations under the simulated muscle load were over-constrained by all the reconstruction techniques, and more so by DBR-HST.

Single-bundle ACL reconstruction with either patellar tendon or hamstring tendon grafts is widely adopted to potentially restore the normal joint laxity and to return the patients to their pre-injury level of activity. In this analysis, we found that both SBR-BPTB and SBR-HST were capable of restoring the anterior joint laxity to nearly normal. Further, the stability provided by SBR-BPTB was closer to the normal knee than by SBR-HST. Similar observations have been reported in the literature ${ }^{28)}$. In general, single-bundle reconstruction has been reported to provide good clinical outcomes ${ }^{21,29)}$. However, several biomechanical and clinical studies have often associated this technique with rotational instability and a prevalence of degenerative changes even after such a surgical intervention is commonly observed as early as within 15 month after surgery ${ }^{4,5,11-13)}$.

Over the years, several risk factors have been identified for the development of posttraumatic knee osteoarthritis ${ }^{2,7)}$. It remains obscure precisely what disrupts the homeostasis of healthy cartilage, subsequently leading to cartilage degeneration. However, it has been hypothesized by some authors that the disease progression may be accelerated due to abnormal loading of cartilagewhich is a manifestation of joint laxity-at locations that are otherwise unloaded or minimally loaded ${ }^{30)}$. With an objective to better control the rotational joint stability and to potentially mitigate the incidence of osteoarthritis, several anatomical techniques have been proposed. Clinical evidence on the superiority of these relatively new techniques over the traditional single-bundle is sparse $^{21)}$.

Among the three anatomical reconstructions evaluated in this study, DBR-HST and ASTR-HST were shown to provide normal joint stability while STDBR-HST restored the joint stability to a nearly normal condition. Similar to our observations, DBR-HST has been previously reported to provide normal joint stability ${ }^{19,20)}$. Quadriceps muscle action is known to induce anterior tibial translation and internal tibial rotation at low flexion angles. Yet, few studies have investigated the efficacy of ACL reconstructions under physiological loading conditions. The analysis of this study demonstrated that SBR-BPTB, STDBR-HST, ASTR-HST, and 
DBR-HST restored the anterior joint stability to a normal condition while the SBR-HST resulted in a nearly normal anterior joint stability under the action of simulated quadriceps load. All the reconstructions closely restored the medial-lateral tibial translations of the normal knee. However, all the five reconstructions over-constrained the internal tibial rotations, resulting in more externally rotated tibiae compared to their normal knee conditions. Decreased internal tibial rotations have been observed among other studies ${ }^{13,31,32)}$, and such a decrease has been proposed to increase the patellofemoral contact pressure ${ }^{33)}$.

Before interpreting the results of this analysis, it is important to recognize the limitations of this study. Different femoral tunnel positions were used for the single-tunnel reconstructions and hence these variations in the tunnel positions may have influenced the observed outcomes. The sub-physiological loads were used to evaluate the reconstructions due to the technical limitations of the robotic testing system and hence these results many not be generalized to observation under actual physiological conditions. All of the studies evaluated the efficacies of the ACL reconstructions in cadaveric specimens and hence ignoring several intricacies of physiological condition. Nonetheless, all of the studies used in this analysis were conducted under stringently controlled laboratory conditions, which provided valuable information on the efficacies of various ACL reconstructions at timezero.

In summary, all the ACL reconstructions provided either normal or nearly normal anterior joint stability and over-constrained the internal tibial rotation. However, nearly normal may not be an adequate outcome, especially considering several reports of repeated giving-way and the high prevalence of osteoarthritis. The strides made in ACL research over the last two decades have significantly improved our understanding of this complex structure and its behavior. However, much progress in further refining the reconstruction techniques remains to be realized.

\section{Conflict of Interest}

No potential conflict of interest relevant to this article was reported.

\section{References}

1. Brophy RH, Zeltser D, Wright RW, Flanigan D. Anterior cruciate ligament reconstruction and concomitant articular cartilage injury: incidence and treatment. Arthroscopy. 2010; 26:112-20
2. Keays SL, Newcombe PA, Bullock-Saxton JE, Bullock MI, Keays AC. Factors involved in the development of osteoarthritis after anterior cruciate ligament surgery. Am J Sports Med. 2010;38:455-63.

3. Spindler KP, Wright RW. Clinical practice: anterior cruciate ligament tear. N Engl J Med. 2008;359:2135-42.

4. Asano H, Muneta T, Ikeda H, Yagishita K, Kurihara Y, Sekiya I. Arthroscopic evaluation of the articular cartilage after anterior cruciate ligament reconstruction: a short-term prospective study of 105 patients. Arthroscopy. 2004;20:474-81.

5. Liden M, Sernert N, Rostgard-Christensen L, Kartus C, Ejerhed L. Osteoarthritic changes after anterior cruciate ligament reconstruction using bone-patellar tendon-bone or hamstring tendon autografts: a retrospective, 7-year radiographic and clinical follow-up study. Arthroscopy. 2008;24:899-908.

6. Lohmander LS, Ostenberg A, Englund M, Roos H. High prevalence of knee osteoarthritis, pain, and functional limitations in female soccer players twelve years after anterior cruciate ligament injury. Arthritis Rheum. 2004;50:3145-52.

7. Oiestad BE, Engebretsen L, Storheim K, Risberg MA. Knee osteoarthritis after anterior cruciate ligament injury: a systematic review. Am J Sports Med. 2009;37:1434-43.

8. van der Hart CP, van den Bekerom MP, Patt TW. The occurrence of osteoarthritis at a minimum of ten years after reconstruction of the anterior cruciate ligament. J Orthop Surg Res. 2008;3:24.

9. Biau DJ, Tournoux C, Katsahian S, Schranz P, Nizard R. ACL reconstruction: a meta-analysis of functional scores. Clin Orthop Relat Res. 2007;458:180-7.

10. Freedman KB, D’Amato MJ, Nedeff DD, Kaz A, Bach BR Jr. Arthroscopic anterior cruciate ligament reconstruction: a metaanalysis comparing patellar tendon and hamstring tendon autografts. Am J Sports Med. 2003;31:2-11.

11. Georgoulis AD, Ristanis S, Chouliaras V, Moraiti C, Stergiou $\mathrm{N}$. Tibial rotation is not restored after ACL reconstruction with a hamstring graft. Clin Orthop Relat Res. 2007;454:8994.

12. Ristanis S, Stergiou N, Patras K, Tsepis E, Moraiti C, Georgoulis AD. Follow-up evaluation 2 years after ACL reconstruction with bone-patellar tendon-bone graft shows that excessive tibial rotation persists. Clin J Sport Med. 2006;16: 111-6.

13. Tashman S, Collon D, Anderson K, Kolowich P, Anderst W. Abnormal rotational knee motion during running after anterior cruciate ligament reconstruction. Am J Sports Med. 2004;32:975-83. 
14. Gadikota HR, Seon JK, Kozanek M, Oh LS, Gill TJ, Montgomery KD, Li G. Biomechanical comparison of singletunnel-double-bundle and single-bundle anterior cruciate ligament reconstructions. Am J Sports Med. 2009;37:962-9.

15. Kondo E, Yasuda K, Azuma H, Tanabe Y, Yagi T. Prospective clinical comparisons of anatomic double-bundle versus single-bundle anterior cruciate ligament reconstruction procedures in 328 consecutive patients. Am J Sports Med. 2008; 36:1675-87.

16. Rue JP, Ghodadra N, Bach BR Jr. Femoral tunnel placement in single-bundle anterior cruciate ligament reconstruction: a cadaveric study relating transtibial lateralized femoral tunnel position to the anteromedial and posterolateral bundle femoral origins of the anterior cruciate ligament. Am J Sports Med. 2008;36:73-9.

17. Tsuda E, Ishibashi Y, Fukuda A, Tsukada H, Toh S. Comparable results between lateralized single- and double-bundle ACL reconstructions. Clin Orthop Relat Res. 2009;467:104255.

18. Seon JK, Gadikota HR, Wu JL, Sutton K, Gill TJ, Li G. Comparison of single- and double-bundle anterior cruciate ligament reconstructions in restoration of knee kinematics and anterior cruciate ligament forces. Am J Sports Med. 2010;38:1359-67.

19. Song EK, Oh LS, Gill TJ, Li G, Gadikota HR, Seon JK. Prospective comparative study of anterior cruciate ligament reconstruction using the double-bundle and single-bundle techniques. Am J Sports Med. 2009;37:1705-11.

20. Yagi M, Wong EK, Kanamori A, Debski RE, Fu FH, Woo SL. Biomechanical analysis of an anatomic anterior cruciate ligament reconstruction. Am J Sports Med. 2002;30:660-6.

21. Meredick RB, Vance KJ, Appleby D, Lubowitz JH. Outcome of single-bundle versus double-bundle reconstruction of the anterior cruciate ligament: a meta-analysis. Am J Sports Med. 2008;36:1414-21.

22. Aglietti P, Zaccherotti G, Simeone AJ, Buzzi R. Anatomic versus non-anatomic tibial fixation in anterior cruciate ligament reconstruction with bone-patellar tendon-bone graft. Knee Surg Sports Traumatol Arthrosc. 1998;6 Suppl 1:S43-8.

23. Caborn DN, Chang HC. Single femoral socket double-bundle anterior cruciate ligament reconstruction using tibialis anterior tendon: description of a new technique. Arthroscopy. 2005;21:1273.
24. Gadikota HR, Wu JL, Seon JK, Sutton K, Gill TJ, Li G. Single-tunnel double-bundle anterior cruciate ligament reconstruction with anatomical placement of hamstring tendon graft: can it restore normal knee joint kinematics? Am J Sports Med. 2010;38:713-20.

25. Ho JY, Gardiner A, Shah V, Steiner ME. Equal kinematics between central anatomic single-bundle and double-bundle anterior cruciate ligament reconstructions. Arthroscopy. 2009;25:464-72.

26. Shino K, Nakata K, Nakamura N, Toritsuka Y, Horibe S, Nakagawa S, Suzuki T. Rectangular tunnel double-bundle anterior cruciate ligament reconstruction with bone-patellar tendon-bone graft to mimic natural fiber arrangement. Arthroscopy. 2008;24:1178-83.

27. Yoo JD, Papannagari R, Park SE, DeFrate LE, Gill TJ, Li G. The effect of anterior cruciate ligament reconstruction on knee joint kinematics under simulated muscle loads. Am J Sports Med. 2005;33:240-6.

28. Woo SL, Kanamori A, Zeminski J, Yagi M, Papageorgiou C, $\mathrm{Fu} \mathrm{FH}$. The effectiveness of reconstruction of the anterior cruciate ligament with hamstrings and patellar tendon. A cadaveric study comparing anterior tibial and rotational loads. J Bone Joint Surg Am. 2002;84:907-14.

29. Lewis PB, Parameswaran AD, Rue JP, Bach BR Jr. Systematic review of single-bundle anterior cruciate ligament reconstruction outcomes: a baseline assessment for consideration of double-bundle techniques. Am J Sports Med. 2008;36:2028-36.

30. Andriacchi TP, Briant PL, Bevill SL, Koo S. Rotational changes at the knee after ACL injury cause cartilage thinning. Clin Orthop Relat Res. 2006;442:39-44.

31. Nordt WE 3rd, Lotfi P, Plotkin E, Williamson B. The in vivo assessment of tibial motion in the transverse plane in anterior cruciate ligament-reconstructed knees. Am J Sports Med. 1999;27:611-6.

32. Papannagari R, Gill TJ, Defrate LE, Moses JM, Petruska AJ, Li G. In vivo kinematics of the knee after anterior cruciate ligament reconstruction: a clinical and functional evaluation. Am J Sports Med. 2006;34:2006-12.

33. Li G, DeFrate LE, Zayontz S, Park SE, Gill TJ. The effect of tibiofemoral joint kinematics on patellofemoral contact pressures under simulated muscle loads. J Orthop Res. 2004; 22:801-6. 